\title{
Model Study on Neutral Winds in the Ionospheric F- Region and Com- parison with the Equivalent Winds Derived from the Wuhan Ionosonde Data
}

\author{
Jiuhou Lei ${ }^{1}$, Libo Liu ${ }^{1, *}$, Xiaoli Luan ${ }^{1}$, and Weixing Wan ${ }^{1}$ \\ (Manuscript received 19 December 2001, in final form 8 November 2002)
}

\begin{abstract}
A theoretical thermospheric circulation model is introduced in this paper. In the model, the Navier-Stokes equations have been solved to derive horizontal neutral winds based on the atmospheric temperature and densities of neutral species, which at present are taken from the latest atmospheric model (NRLMSISE-00). In this work, the zonal and meridional neutral winds are obtained from our model for seasons at moderate solar activity, mainly in East Asia. The zonal winds generally flow westward from around midnight to afternoon and reverse their direction for the rest of the day in equinox, while the phases have some differences in summer and winter. The main daily variation pattern of meridional winds is daytime poleward and nighttime equatorward in equinox. It is also found that the meridional winds blow almost southward in summer and northward in winter. In the meanwhile, comparisons of winds calculated from our model with those of the HWM93 model are carried out to see whether the models are consistent or not. For zonal winds, the results show good agreement in phases and some discrepancy in magnitudes. Our meridional winds present significant differences with the HWM93 model during solstices, while they remarkably agree in equinoxes. Finally, our model meridional winds are compared with the equivalent winds derived from the ionospheric data in Wuhan $\left(30.6^{\circ} \mathrm{N}, 114.4^{\circ} \mathrm{E}\right)$. The results show much better agreement than with HWM93 model winds at the height of F2 peak.
\end{abstract}

(Key words: Model study, Neutral winds, Ionosphere, Servo theory)

\section{INTRODUCTION}

Considerable experimental and theoretical evidences show that the thermosphere and iono-

${ }^{1}$ Wuhan Ionospheric Observatory, Wuhan Institute of Physics and Mathematics, Chinese Academy of Sciences, Wuhan, P.R.China

* Corresponding Author Address. Dr. Libo Liu, Wuhan lonospheric Obsenvatory, Wuhan Institute of Physics and Mathematics, Chinese Academy of Sciences, Wuhan, 430071, P.R.China E-mail: Iliu@wipm.ac.cn 


\section{TAO, Vol. 14, No. 1, March 2003}

sphere are closely coupled. Describing the accurate picture of important dynamic processes in the ionosphere depends greatly on detailed information of thermospheric winds and other parameters. Much progress has been made to improve our knowledge of neutral winds in both direct and indirect measurements and theoretical models. The neutral winds deduced from incoherent scatter and Fabry-Perot optical interferometers (FPI) measurements have been reported by Roble et al. (1974), Yagi and Dyson (1985), and so on. However, such measurements were mainly carried out at middle latitudes. In addition, another indirect method is to determine the neutral winds from ground-based ionospheric measurements. Based on the simplified servo equations given by Rishbeth (1967) and Rishbeth et al. (1978), two major approaches to deriving the neutral winds have been developed by Buonsanto (1986), Buonsanto et al. (1989) and Miller et al. (1986) respectively. Buonsanto et al. (1989) applied the method suggested by Rishbeth et al. (1978), and assumed the F2 peak appeared at a balance height in the absence of vertical drift and then an applied drift consisting of diffusive drift and the neutral wind along magnetic field line carried the peak to a new level, where the production and loss processes determined the change rate of the electron density. In this approach, besides the ionospheric parameters $\left(\mathrm{hmF} 2\right.$ and foF2), the neutral density, temperature and $\mathrm{O}^{+}-\mathrm{O}$ collision frequency are also required. The output of the servo method is the equivalent wind along the magnetic field line needed to move the ionosphere up and down as observed. This equivalent wind can be expressed as a horizontal neutral wind. Another approach presumes that the variation of the F2 peak is almost linear to the neutral winds (Miller et al. 1986). The linear coefficient can be obtained from simulations using an ionospheric model.

In the early years, to meet the needs of ionospheric study, the calculated neutral winds were based on given empirical atmospheric models, such as the Jacchia model (1971), which gives symmetrical pressure so as to produce symmetrical wind patterns. More recently, an atmospheric neutral model (Hedin et al. 1991) and its newest edition NRLMSISE-O0 (Picone et al. 2002) were developed. The earlier MSIS models have been applied to derive neutral winds, such as by Banerjee et al. (1986) and Walker and Chan (1989), under a one-dimensional assumption. Results of Banerjee et al. (1986) agree well with the radar measurements at St. Santin. In addition, several global three-dimensional thermospheric circulation general models have been developed (Fuller-Rowell and Rees 1980; Roble and Ridley 1994). These theoretical circulation models can output neutral temperature, neutral composition, and neutral winds.

An empirical thermosphere horizontal wind model (HWM93) is available now, which was constructed by Hedin et al. (1996), using satellite and ground-based observations. Care must be paid in employing at low latitudes and the southern hemisphere region, for sparse data are attained at those regions in the model. The VSH model (Killeen 1987) is also available; however, the magnitudes of the $24 \mathrm{~h}$ and $12 \mathrm{~h}$ components and the mean equatorward components are generally too large (Titheridge 1995).

As we know, neutral winds are very important for accurately explaining and modeling Flayer phenomena, such as the daily variation of peak electron density and its height. Furthermore, the maintenance of the nighttime ionosphere and the seasonal anomaly could not be explained without taking the effect of winds into account (Rishbeth 1972). Therefore, more knowledge about neutral winds is essential to understanding the dynamic process and to further model 
study.

As Titheridge (1995) wrote about the thermospheric winds: " Since good measurements are not yet available for many conditions. A simple wind calculation based on atmospheric pressure gradients (from MSIS86 model) is assessed and found wanting". In this paper, our calculations are based on parameters from the NRLMSISE-00 model and IRI2000 model (Bilitza 2001). The Navier-Stokes momentum equation is solved and the result is compared with HWM93 model. Due to some particular features of the equatorial region, such as the equatorial anomaly and so on, we are aiming to develop a self-consistent thermosphere-circulationionosphere model to study the close coupling between thermosphere and ionosphere at mid and low latitudes and the ionosphere model has been described recently by Liu et al. (2000).

\section{A DESCRIPTION OF THE NEUTRAL CIRCULATION MODEL}

The momentum equation for the neutral atmosphere is given as follows (Rishbeth, 1972):

$$
\frac{\partial U}{\partial t}+(U \cdot \nabla) U+2 \Omega \times U=\frac{\mu}{\rho} \nabla^{2} U+v_{n i}(V-U)-\frac{1}{\rho} \nabla p+g \text {, }
$$

where

$$
\rho=\sum_{n} m_{n} n_{n}, \quad p=\left(\sum_{n} n_{n}\right) k_{B} T_{n}, \quad v_{n i}=\frac{\sum_{i} n_{i} m_{i} v_{i n}}{\sum_{n} n_{n} m_{n}} .
$$

$\boldsymbol{U}$ denotes the neutral wind velocity vector; $\Omega$ is the rotational angle velocity of the earth; $m_{n}$, $m_{i}$ are the masses of the neutral species $\mathrm{n}$ and $\mathrm{i}$-th charged particles, respectively; $\rho, \mathrm{p}$ are the total neutral mass density and the total pressure, respectively; $\mu$ is the viscosity coefficient, and the expression for viscosities of individual neutral composites is given by Rees (1989); $v_{i n}$ is the ion-neutral collision frequency, in which the most important collision frequency for $\mathrm{O}^{+}-\mathrm{O}$ is 1.7 times of that calculated by Schunk and Walker (1973), and the parameter $v_{n i}$ expresses the neutral-ion collision frequency; $\boldsymbol{g}$ is the gravity acceleration; $\boldsymbol{V}$ is the ion velocity, which includes the drag effect of neutral winds, drifts due to electric fields, and the fieldaligned diffusion.

Due to the balance between the vertical component of the pressure gradient force and gravitational force, the vertical advection term is very small, so only the horizontal neutral winds are under consideration in the model. The horizontal winds may have large spatial gradients, as suggested by Blum and Harris (1975), so the horizontal advection terms may be significant. Here the non-linear terms are retained. In the geocentric sphere frame $(\gamma, \theta, \phi)$, we have:

$$
\frac{\partial u_{\theta}}{\partial t}=\left(\frac{\mu}{\rho \gamma^{2}} \cot \theta-\frac{u_{\theta}}{\gamma}\right) \frac{\partial u_{\theta}}{\partial \theta}-\frac{u_{\phi}}{\gamma \sin \theta} \frac{\partial u_{\theta}}{\partial \phi}+\frac{\cot \theta}{\gamma} u_{\phi}^{2}+f u_{\phi}-\frac{1}{\rho \gamma} \frac{\partial p}{\partial \theta}
$$




$$
\begin{aligned}
& +\frac{\mu}{\rho} \frac{\partial^{2} u_{\theta}}{\partial \gamma^{2}}+\frac{\mu}{\rho \gamma^{2}} \frac{\partial^{2} u_{\theta}}{\partial \theta^{2}}+v_{n i}\left(v_{\theta}-u_{\theta}\right) \\
\frac{\partial u_{\phi}}{\partial t}= & \left(\frac{\mu}{\rho \gamma^{2}} \cot \theta-\frac{u_{\theta}}{\gamma}\right) \frac{\partial u_{\phi}}{\partial \theta}-\frac{u_{\phi}}{\gamma \sin \theta} \frac{\partial u_{\phi}}{\partial \phi}-\frac{\cot \theta}{\gamma} u_{\theta} u_{\phi}-f u_{\theta}-\frac{1}{\rho \gamma \sin \theta} \frac{\partial p}{\partial \phi} \\
& +\frac{\mu}{\rho} \frac{\partial^{2} u_{\phi}}{\partial \gamma^{2}}+\frac{\mu}{\rho \gamma^{2}} \frac{\partial^{2} u_{\phi}}{\partial \theta^{2}}+v_{n i}\left(v_{\phi}-u_{\phi}\right) .
\end{aligned}
$$

Where $u_{\theta}$ and $u_{\phi}$ are the southward and eastward components of horizontal neutral winds; $f=2 \Omega \cos \theta$ is the Coriolis parameter, and where $\Omega$ is the rotational angle velocity; $\gamma, \theta, \phi$ are the distance from the earth center, co-latitude and longitude respectively; And $v_{\theta}$ and $v_{\phi}$ are the southward and eastward components of ion velocity $\mathbf{V}$.

Assuming the longitudinal variation of winds can be converted into their time variation, the approximation is adopted by Salah and Holt (1974),

$$
\frac{\partial}{\partial \phi}=\frac{1}{\Omega} \frac{\partial}{\partial t} .
$$

Under the above assumption, Equations (2) and (3) become

$$
\begin{aligned}
\left(1+\frac{u_{\phi}}{\gamma \omega \sin \theta}\right) \frac{\partial u_{\theta}}{\partial t}= & \left(\frac{\mu}{\rho \gamma^{2}} \cot \theta-\frac{u_{\theta}}{\gamma}\right) \frac{\partial u_{\theta}}{\partial \theta}+\frac{\mu}{\rho \gamma^{2}} \frac{\partial^{2} u_{\theta}}{\partial \theta^{2}}+\frac{\cot \theta}{\gamma} u_{\phi}^{2}+\frac{\mu}{\rho} \frac{\partial^{2} u_{\theta}}{\partial \gamma^{2}} \\
& +A_{1} u_{\theta}+B_{1} u_{\phi}+F_{1}+G_{1}, \\
\left(1+\frac{u_{\phi}}{\gamma \omega \sin \theta}\right) \frac{\partial u_{\phi}}{\partial t}= & \left(\frac{\mu}{\rho \gamma^{2}} \cot \theta-\frac{u_{\theta}}{\gamma}\right) \frac{\partial u_{\phi}}{\partial \theta}+\frac{\mu}{\rho \gamma^{2}} \frac{\partial^{2} u_{\phi}}{\partial \theta^{2}}-\frac{\cot \theta}{\gamma} u_{\theta} u_{\phi}+\frac{\mu}{\rho} \frac{\partial^{2} u_{\phi}}{\partial \gamma^{2}} \\
& +A_{2} u_{\theta}+B_{2} u_{\phi}+F_{2}+G_{2} .
\end{aligned}
$$

Where the coefficients $A_{i}, B_{i}, F_{i}, G_{i}(\mathrm{i}=1,2)$ are given as Roble et al. (1974).

In this paper, the concentrations and temperature of neutral atmosphere are not calculated by way of the TIMEGCM model (Roble and Ridley 1994), but are provided by the NRLMSISE00 model instead, and the ion densities by the IRI 2000 model. The electric field model of Richmond et al. (1980) is employed to yield the upward/poleward and eastward/westward E $\times$ B drift.

The two momentum equations are solved numerically by the operator-splitting method as our ionospheric model (Liu et al. 2000) in the height and co-latitude directions. The integration was carried out with a latitude grid of $2^{\circ}$ and a height step of $4 \mathrm{~km}$ at the altitudes from 80 to $500 \mathrm{~km}$. The time step is 10 minutes. We assume $u_{\theta}=u_{\phi}=0$ at the lower boundary, and $\frac{\partial u_{\theta}}{\partial \gamma}=\frac{\partial u_{\phi}}{\partial \gamma}=0$ at the upper boundary. 


\section{CALCULATIONS AND RESULTS}

At present, we are determined to assess the validity of our thermospheric circulation model. The calculated winds over Wuhan at near equinoxes are shown in the upper panel of Fig. 1. The zonal winds flow eastward from afternoon to midnight, and westward for the rest of the day. The meridional winds in the F layer blow northward in the daytime and southward at night. The magnitudes of winds in nighttime are larger than those in the daytime because of less ion-drag. Our results show some similarities to winds calculated by Antoniadis (1976) using the one-dimensional neutral momentum equations, over Millstone Hill $\left(42.6^{\circ} \mathrm{N}, 71\right.$. $5^{\circ} \mathrm{W}$ ) under higher solar conditions, based on the ionospheric parameters induced from scatter radar techniques. Our results generally agree with those from the HWM93 model, except that the morning phase transitions of our model winds occur 2 hours earlier than those of the HWM93 model. And, the calculated winds are larger than the HWM93 winds as a whole. This indicates either the failure in predication of HWM93 model or the physical inconsistency between MSIS and HWM93 models at the latitude of Wuhan. In other words, if the MSIS and HWM93 models both represent the actual situations, they should provide similar thermospheric winds, i.e. that they are in physical consistency. This is also why we develop a thermospheric wind model to provide physical consistent atmospheric parameters and thermospheric winds at present.
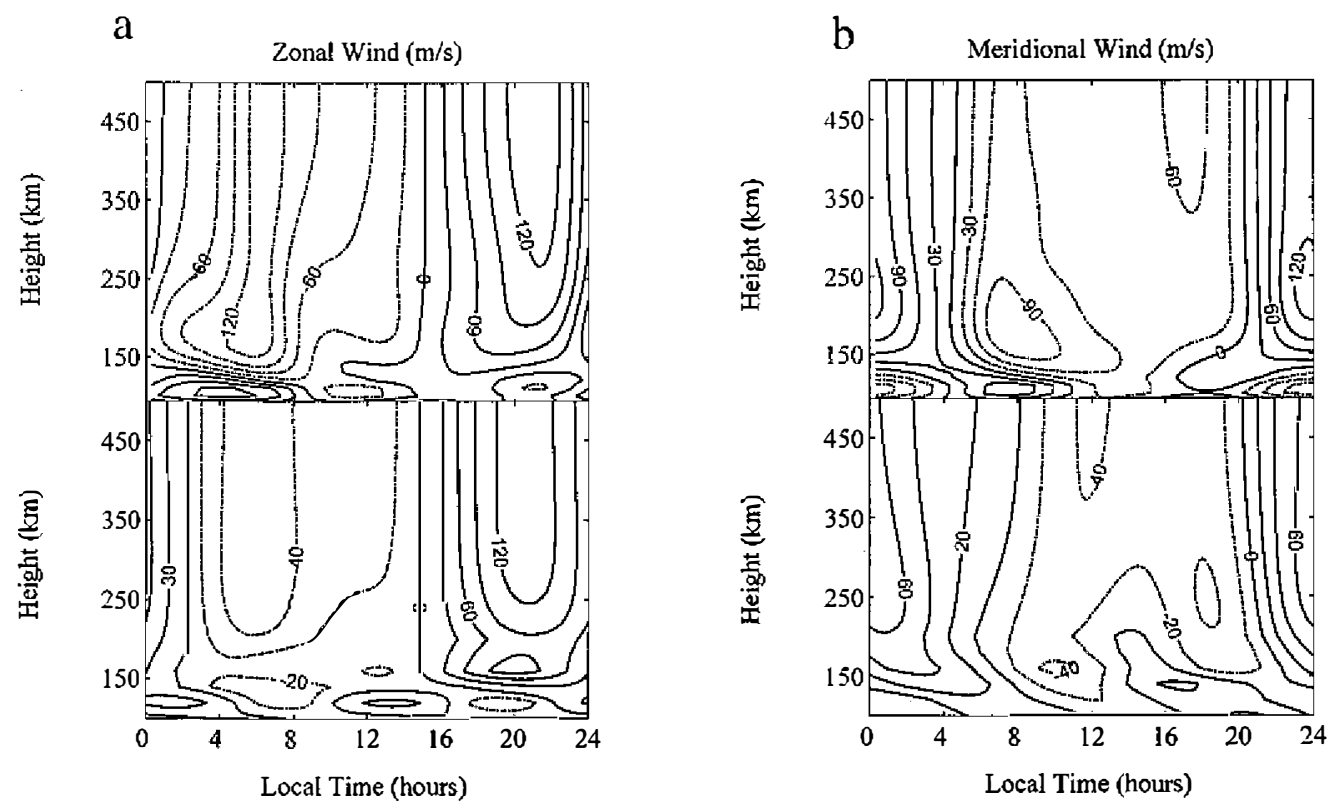

Fig. 1. Contours of our model calculated horizontal neutral winds, (a) zonal wind (positive eastward) and (b) meridional wind (positive southward) to compare with winds calculated from HWM93 over Wuhan for near equinox. The upper and bottom panels are for our model and HWM93, respectively. 
TAO, Vol. 14, No. 1, March 2003

The diurnal and seasonal variations of neutral winds under middle solar conditions and quiet magnetic activity (Solar $10.7 \mathrm{~cm}$ flux index, F107=120, and $\mathrm{Ap}=4$ ) for East Asia (geographic longitude $120^{\circ} \mathrm{E}$ ) are shown in Fig. 2 corresponding with equinox, summer solstice and winter solstice (day number $80,180,360$, respectively).

During equinox periods, the zonal wind pattern is relatively simple, whose direction generally changes around $0400 \mathrm{LT}$ and in the afternoon. In the magnetic equatorial region (about $10^{\circ} \mathrm{N}$ ) the contours show daytime westward winds with maximum values at noon and nighttime eastward winds with maximum values after sunset. Meridional winds blow away from the geographic equator to polar latitudes during daytime and reverse at nighttime. Obviously a highly asymmetric wind exists with respect to the geographic equator. In addition, convergence winds appear at about $10^{\circ} \mathrm{N}$ (around the magnetic equator) during nighttime rather than at the geographic equator.

Our results under equinoctial conditions have some differences from those of earlier works. The differences may be mainly attributed to our asymmetrical pressure distribution. Blum and Harris (1975) calculated the global winds, and attained a symmetrical wind pattern, due to a symmetrical pressure system based on the Jacchia thermospheric model. In their calculations,
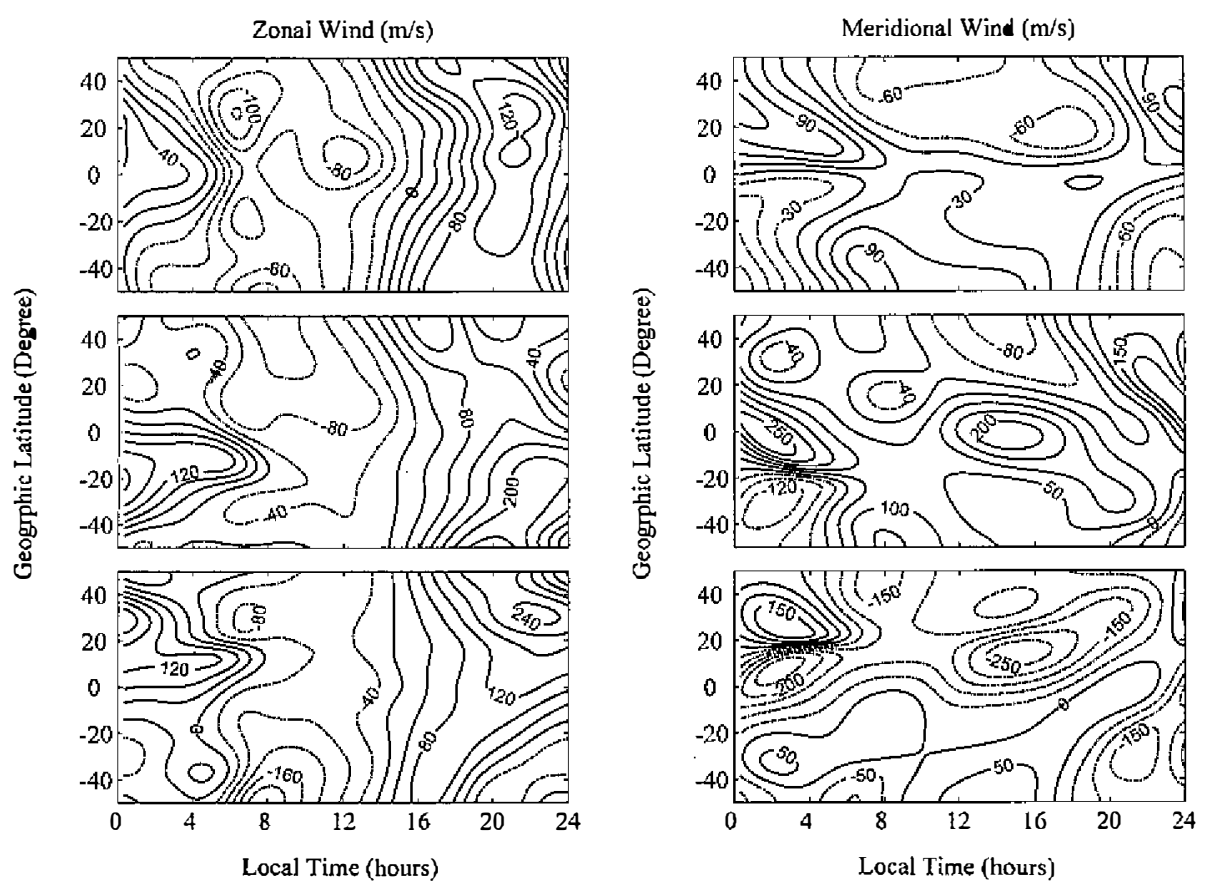

Fig. 2. Contours of zonal and meridional wind for a geographic longitude of $120^{\circ} \mathrm{E}$ at $300 \mathrm{~km}$ from our model. The panels from top to bottom correspond to zonal and meridional winds at equinox, summer solstice and winter solstice. 
the bulge and the minimum of the pressure are centered at $1430 \mathrm{LT}$ and $0300 \mathrm{LT}$ at the geographic equator, respectively.

The winds are more complex both in summer and winter than during equinoxes. For summer, the zonal winds change their directions at midnight and at $1400 \mathrm{LT}$ in the northern hemisphere, while change at $0600 \mathrm{LT}$ or so and at $1400 \mathrm{LT}$ in the southern hemisphere, which results in the diurnal averaged zonal wind westward in the northern hemisphere and eastward in the south hemisphere. For winter, the averaged zonal winds are opposite in the two hemispheres. The predominantly meridional winds are southward in summer. Strong southward winds with speeds of greater than $100 \mathrm{~ms}^{-1}$ occur in $1200-1600 \mathrm{LT}$ around $10^{\circ} \mathrm{N}$. But, in winter, the predominant meridional winds are northward. Especially, in the magnetic equator region the maximum wind reaches speed of $200 \mathrm{~ms}^{-1}$. Neutral winds calculated by Walker and Chan (1989) show some similarities to the results presented here.

The pressure distributions for summer and winter solstice, which are different from those at equinoctial conditions, can perfectly explain the results of our calculated winds. In summer and winter, the pressure reaches its lowest at mid-night and then reaches its highest about at $1400 \mathrm{LT}$ at latitude $20^{\circ} \mathrm{N}$ and $20^{\circ} \mathrm{S}$ or so, respectively. The high asymmetry explains well why the predominant winds are southward in summer and northward in winter, as mentioned by Hari and Murthy (1995). Besides the predominant effect of pressure gradient, the viscosity and ion drag become secondary effects on thermospheric dynamics especially in the $\mathrm{F}$ region, which was discussed in detail by Rishbeth (1972).

The HWM93 model winds are plotted in Fig. 3 to compare with calculated winds at corresponding seasons (Fig. 2) in the same geophysical conditions. The zonal winds are in good agreement in phase, but the magnitudes have some differences. In the meanwhilc the phase of the meridional winds is in good agreement during equinox but greatly discrepant during solstices. The meridional magnitudes present clear differences in all seasons. The HWM93 meridional winds are less by a factor of 1-2 than ours at sometimes especially in summer and winter seasons. As we know, the two model winds are calculated using atmospheric data from the empirical NRLMSISE-00 and HWM93 models, which are based on satellite and ground-based measurements. However, there is only one ground-based station's data in the equatorial region for constructing the HWM93 model. And, in the northern hemisphere, data are limited at middle and high latitudes in summer. At the same time, in the southern hemisphere few data were available in summer and equinoxes at low-middle latitudes, and no data were obtained for the daytime in winter. As pointed out in the review by Titheridge (1995), the errors may reach $50-100 \mathrm{~ms}^{-1}$ at some times. Although the HWM93 model is used frequently at present, its accuracy is a great hindrance to model study for understanding the ionospheric dynamic processes, especially at low latitudes.

Figure 4 shows the diurnal and seasonal variations of neutral winds at $300 \mathrm{~km}$ over Wuhan. Apparently, the zonal winds have a predominantly diurnal component. The zonal curves have an eastward turning at about $1400 \mathrm{LT}$ and reversal to westward winds at $0100 \mathrm{LT}, 0000 \mathrm{LT}$ and $0300 \mathrm{LT}$ for equinox, summer and winter, respectively. The eastward winds appear stronger in winter than in equinox and summer. The variations of meridional winds are more complicated. For equinox, the phase transition time occurs at about $0400 \mathrm{LT}$ in the morning and at about 2000LT at night, but for summer there are four phase transition times at about 
TAO, Vol. 14, No. 1, March 2003
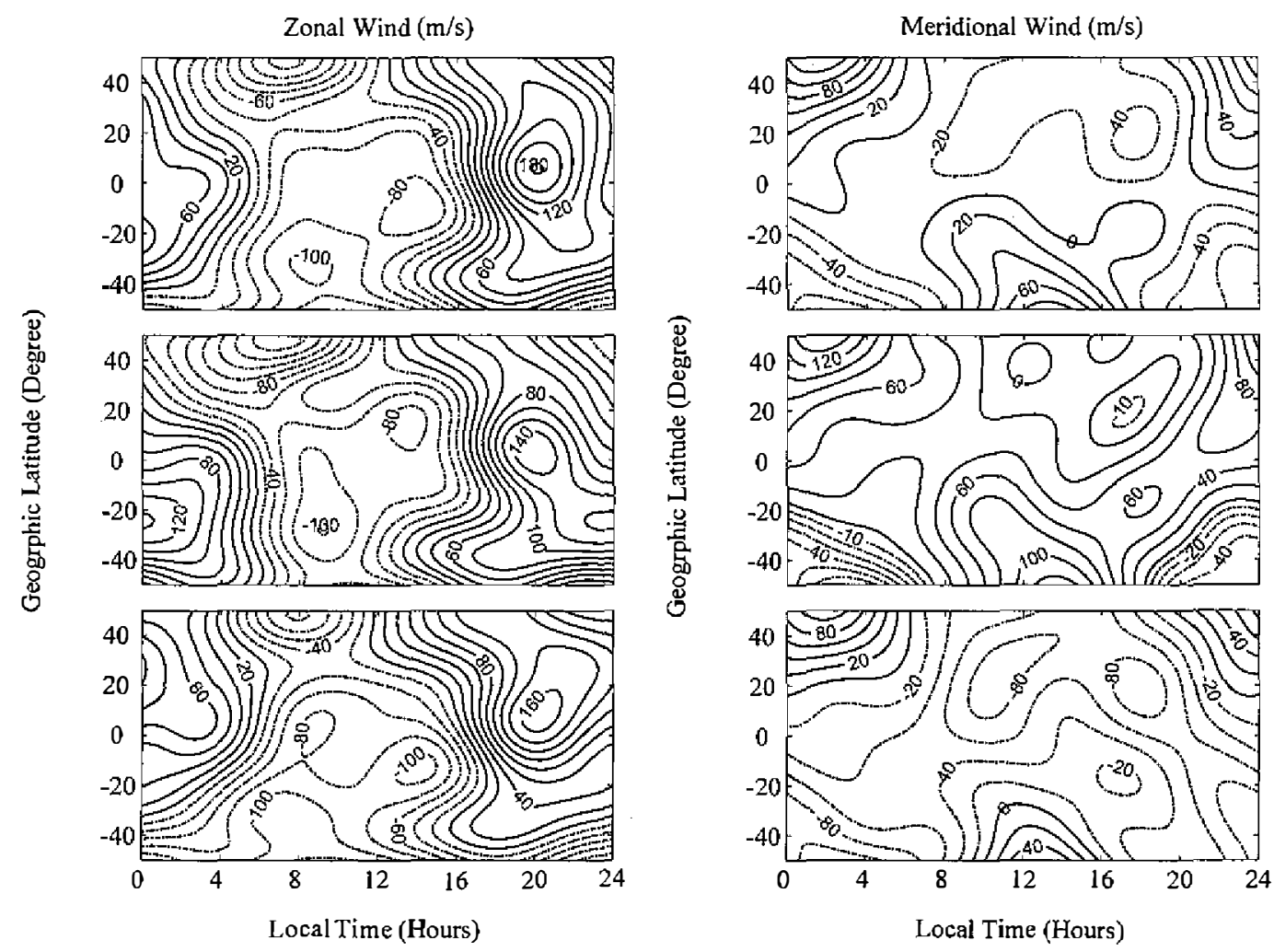

Fig. 3. Similar to Fig. 2, but from the HWM93 model.

$0200 \mathrm{LT}, 0400 \mathrm{LT}, 0900 \mathrm{LT}$ and $1800 \mathrm{LT}$, respectively. And, for winter, the phase transition time appears at about $0400 \mathrm{LT}$, but the night transition time is delayed to $2330 \mathrm{LT}$. The average meridional amplitude shows weak equtorward in summer and strong poleward component in winter. The meridional winds have significant diurnal amplitude in equinox, but larger $12 \mathrm{~h}$ and $8 \mathrm{~h}$ components superpose on the diurnal amplitude in summer and winter. Certainly, the phase has some variations due to altitude and geographical conditions.

Figure 5 depicts the diurnal variation of foF2 and $\mathrm{hmF} 2$, and comparison of southward winds resulting from model simulated winds, with servo equivalent winds and the HWM93 model winds for three quiet geomagnetic days over Wuhan. In this paper, the Buonsanto et al. (1989) method is used to derive the equivalent winds from the ionospheric data. Using the atmospheric model (NRLMSISE-00), the diffusion coefficient and the neutral scale height can be obtained. After calculating the balance height, the servo winds can be derived from the ionospheric parameters hmF2 and foF2. At middle latitudes, the effect of electric fields to the drift is expected to be small and we can compare the equivalent winds with winds from our model and from the HWM93 model. It is obvious that the servo winds have distinct day-to-day variations and the drifts are downward in daytime and upward in nighttime. This is consistent 

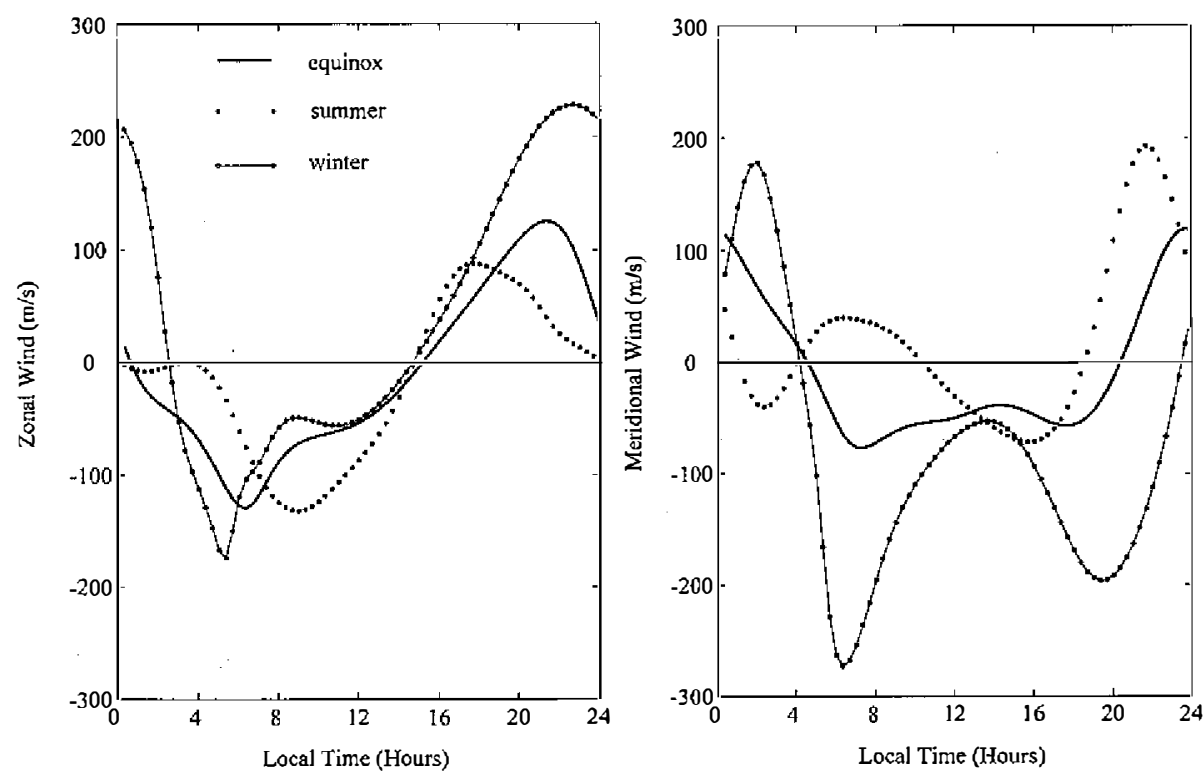

Fig. 4. The diurnal and seasonal variations of neutral winds obtained from our model at $300 \mathrm{~km}$ over Wuhan.

with the meridional wind blowing to the pole in the daytime and turning equatorward at night. Our model winds are in very good agreement with the equivalent winds, except that there is a larger differences for the periods of sunrise and sunset especially. At the same time, comparison of HWM winds with the equivalent winds shows general agreement. Both share the variation tendency, besides striking differences in magnitudes.

\section{DISSCUSION AND SUMMARY}

We have presented a theoretical thermospheric circulation model, which will be a part of our self-consistent thermospheric-circulation-ionospheric model. Based on the NRLMSISE00 model, the diurnal and seasonal variations of neutral winds calculated by our model are presented, mainly for the East Asia sector. The results show that the calculated winds have apparently diurnal and seasonal variations. The daily zonal winds are generally westward from around $0400 \mathrm{LT}$ to afternoon and eastward for the rest of the day for equinox. In summer and winter, the transition times vary with latitude. As for the meridional component, during equinoxes, winds mainly blow towards the poles from the geographic equator at daytime, while at nighttime reverse direction. The predominantly meridional winds are southward in summer and northward in winter. And, the meridional winds show a weak equatorward daily 
TAO, Vol. 14, No. l, March 2003

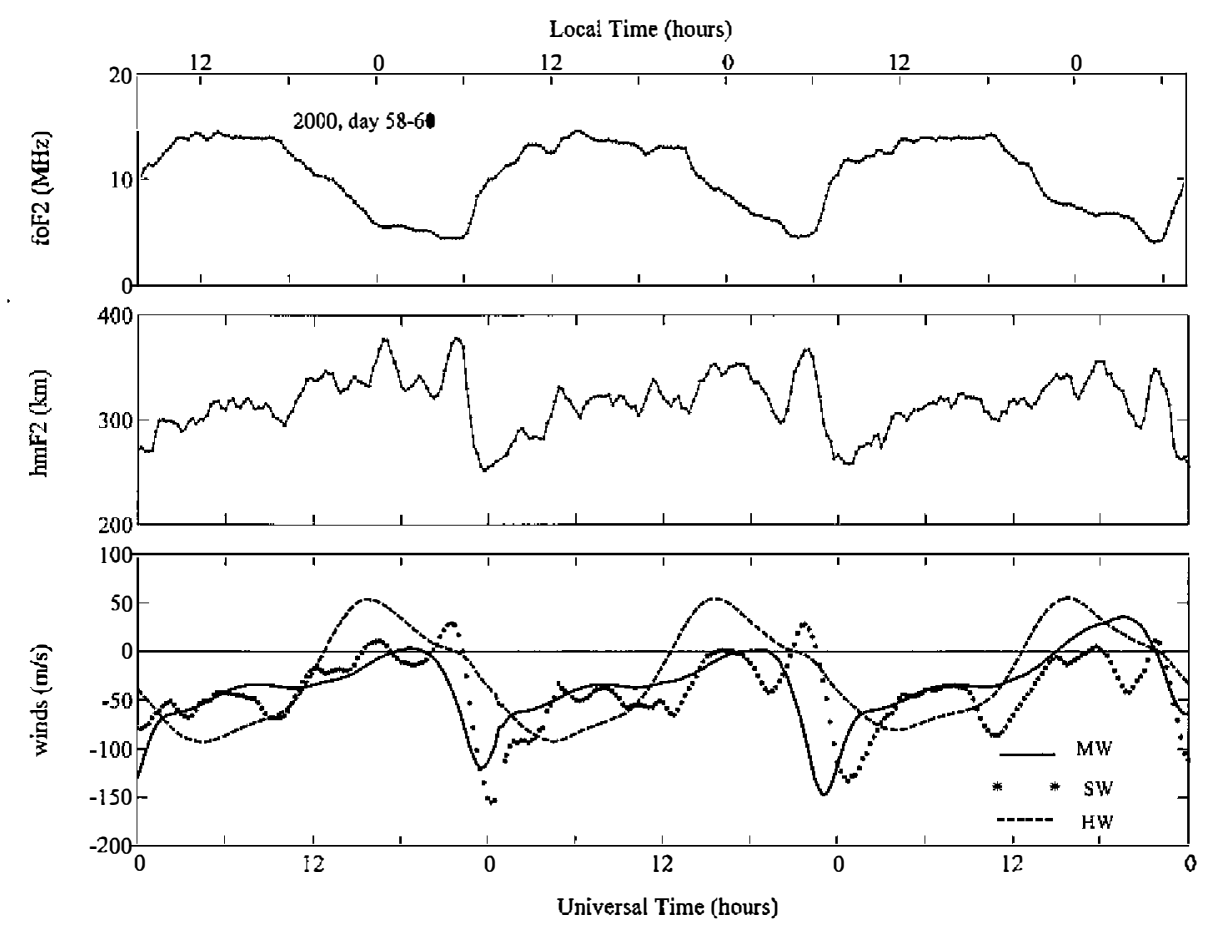

Fig. 5. The diurnal variation of foF2 and hmF2, and comparison of south ward winds resulting from model simulated winds (MW), servo equivalent winds (SW) and the HWM93 model winds (HW) during the No. 58-60 day in 2000.

mean component for summer and strong poleward daily mean component for winter, and large $12 \mathrm{~h}$ and $8 \mathrm{~h}$ components are superposed on the diurnal component for both seasons. At the same time, our model winds are compared with those of the HWM93 model. The two methods agree better during equinoxes than during other seasons, and zonal winds agree better than meridional winds. Our model winds are generally larger than those of HWM93 model. Also, a comparison of model winds with the equivalent winds is carried out. Our model winds are in very good agreement with the equivalent winds, and the winds predicted from the HWM model are in general agreement with the equivalent winds but show striking differences in magnitudes.

Our model also includes some uncertainty factors, such as the poor knowledge about the $\mathrm{O}^{+}-\mathrm{O}$ collision frequency and neutral compositions calculated from the MSIS model. A number of improvements are to be carried out for the current simple model. First, the full NavierStokes equations will be solved to develop a three-dimensional neutral thermospheric model. Second, the theoretical electric field model will be included rather than the empirical model of Richmond et al. (1980), which is only based on measurements at the European sector as well as the American sector. The uncertainty of the empirical model has been discussed fully by Walker and Chan (1989). Third, a self-consistent thermosphere-circulation-ionosphere model 
should be developed. Our developed ionosphere model (Tu et al. 1997; Liu et al. 2000) is expected to be used. After the above improvements, we will understand the thermospheric dynamics and its interaction with ionospheric plasma more completely.

Acknowledgments The codes of NRLMSISE-00 model, HWM93 model, and IRI2000 model are provided by the World Data Center-A. This research was supported by National Natural Science Foundation of China (40274054) and National Important Basic Research Project (G2000078407).

\section{REFERENCES}

Antoniadis, D. A., 1976: Thermosphere winds and exospheric temperatures from incoherent scatter radar measurements in four seasons. J. Atmos. Terr. Phys., 38, 187-195.

Banerjee, M., A. R. Jain, and C. S. G. K. Setty, 1986: Mid-latitude meridional neutral winds in the quiet ionosphere: a comparison of radar observations with those derived from the MSIS model. J. Atmos. Terr. Phys., 48, 573-578.

Bilitza, D., 2001: International reference ionosphere 2000, Radio Sci., 36, 261-275.

Blum, P. W., and I. Harris, 1975: Full non-linear treatment of the global thermospheric wind system- II. Results and comparison with observation. J. Atmos. Terr. Phys., 37, 213235.

Buonsanto, M. J., 1986: Seasonal variations of day-time ionisation flows inferred from a comparison of calculated and observed NmF2. J. Atmos. Terr. Phys., 48, 365-373.

Buonsanto, M. J., J. E. Salah, K. L. Miller, W. L. Oliver, R. G. Burnside, and P. G. Richards, 1989: Observations of neutral circulation at mid-latitude during the equinox transition study. J. Geophys. Res., 94, 16987-16997.

Fuller-Rowell, T. J., and D. Rees, 1980: A three-dimensional, time-dependent global model of the thermosphere. J. Atmos. Sci., 37, 2545-2657.

Hari, S. S., and B. V. K. Murthy, 1995: Seasonal variations of equatorial night-time thermospheric meridional winds. J. Atmos. Terr. Phys., 57, 1241-1246.

Hedin, A. E., 1991: Extension of the MSIS thermospheric model into the middle and lower atmosphere. J. Geophys. Res., 96, 1159-1172.

Hedin, A. E., E. L. Fleming, A. H. Manson, F. J. Schmidlin, S. K. Avery, R. R. Clark, S. J. Franke, G. J. Fraser, T. Tsuda, F. Vial, and R. A. Vincent, 1996: Empirical wind model for the upper, middle and lower atmosphere. J. Atmos. Terr. Phys., 58, 1421-1447.

Jacchia, L. G., 1971: Revised static models of thermosphere and exosphere with empirical temperature profiles. Special Report, Smithsonian Astrophys. Obs., 332.

Killeen, T. L., 1987: Energtics and dynamics of the earth's thermosphere. Rev. Geophys., 25, 433-454.

Liu, L. B., W. X. Wan, J. N. Tu, and Z. T. Bao, 2000: Modeling of the ionospheric response to the solar eclipse of 24 October 1995. TAO, 11, 543-554.

Miller, K. L., D. G. Torr, and P. G. Richards, 1986: Meridional winds in the thermosphere derived from measurement of F2 layer height. J. Geophys. Res., 91, 4531-4535. 
Picone, J. M, A. E. Hedin, D. P. Drob, and A. C. Aikin, 2002: NRLMSISE-00 empirical model of the atmosphere: statistical comparisons and scientific issues. J. Geophys. Res., submitted.

Rees, M. H., 1989: Physics and Chemistry of the Upper Atmosphere, Cambridge Univ. Press, Cambridge, 125-126.

Richmond, A. D., M. Blanc, B. A. Emery, R. H. Wand, B. G. Fejer, R. F. Woodman, S. Ganguly, P. Amayenc, R. A. Behnke, C. Calderon, and J. V. Evans, 1980: An empirical model of quiet day ionospheric electric fields at middle and low latitude. J. Geophys. Res., 85, 4658-4664.

Rishbeth, H., 1967: The effect of winds on the ionospheric F2-peak. J. Atmos. Terr. Phys., 29, 225-238.

Rishbeth, H., 1972: Thermospheric winds and the F-region: A review. J. Atmos. Terr. Phys., 34, 1-47.

Rishbeth, H., S. Ganguly, and J. C. G. Walker, 1978: Field-aligned and field-perpendicular velocities in the ionospheric F2-layer. J. Atmos. Terr. Phys., 40, 767-784.

Roble, R. G., B. A. Emery, J. E. Salah, and P. B. Hays, 1974: Diurnal variation of the neutral thermospheric winds determined from incoherent scatter radar data. J. Geophys. Res., 79, 2868-2876.

Roble, R. G., and E. C. Ridley, 1994: A thermosphere-ionosphere-mesosphere-electrodynamics general circulation model (time-GCM): Equinox solar cycle minimum simulations (30-500km). Geophys. Res. Lett., 21, 417-420.

Salah, J. E., and J. M. Holt, 1974: Midlatitude thermospheric winds from incoherent scatter radar and theory. Radio Sci., 9, 301-313.

Schunk, R. W., and J. C. G. Walker, 1973: Theoretical ion densities in the lower ionosphere. Planet. Space Sci., 21, 1875-1896.

Titheridge, J. E., 1995: Winds in the ionosphere- a review. J. Atmos. Terr. Phys., 57, 16811714.

Tu, J. N., L. B. Liu, Z. T. Bao, 1997: A low latitude ionospheric theoretical model. Chinese J. Space Physics, 17, 212-219 (in Chinese).

Walker, G. O., and H. F. Chan, 1989: Computer simulations of the seasonal variations of the ionospheric equatorial anomaly in East Asia under solar minimum conditions. J. Atmos. Terr. Phys., 51, 953-974.

Yagi, T., and P. L. Dyson, 1985: The response of the mid-latitude thermospheric wind to magnetic activity. Planet. Space Sci., 33, 461-467. 